Témoigner Témoigner. Entre histoire et mémoire

Getuigen Revue pluridisciplinaire de la Fondation Auschwitz

118 | 2014

Au nom des victimes. Dictature et terreur d'État en Argentine, Chili et Uruguay

\title{
Ida, ou nous irons tous au paradis
}

Ida, or We'll all go to Heaven

Ida, of we gaan allemaal naar de hemel

\section{Gabriel Raichman}

\section{(2) OpenEdition \\ Journals}

Édition électronique

URL : http://journals.openedition.org/temoigner/1234

DOI : $10.4000 /$ temoigner.1234

ISSN : 2506-6390

\section{Éditeur :}

Éditions du Centre d'études et de documentation Mémoire d'Auschwitz, Éditions Kimé

\section{Édition imprimée}

Date de publication : 1 octobre 2014

Pagination : 23-26

ISBN : 978-2-84174-674-3

ISSN : 2031-4183

Référence électronique

Gabriel Raichman, «Ida, ou nous irons tous au paradis », Témoigner. Entre histoire et mémoire [En ligne], 118 | 2014, mis en ligne le 01 octobre 2015, consulté le 23 octobre 2020. URL : http:// journals.openedition.org/temoigner/1234; DOI : https://doi.org/10.4000/temoigner.1234 


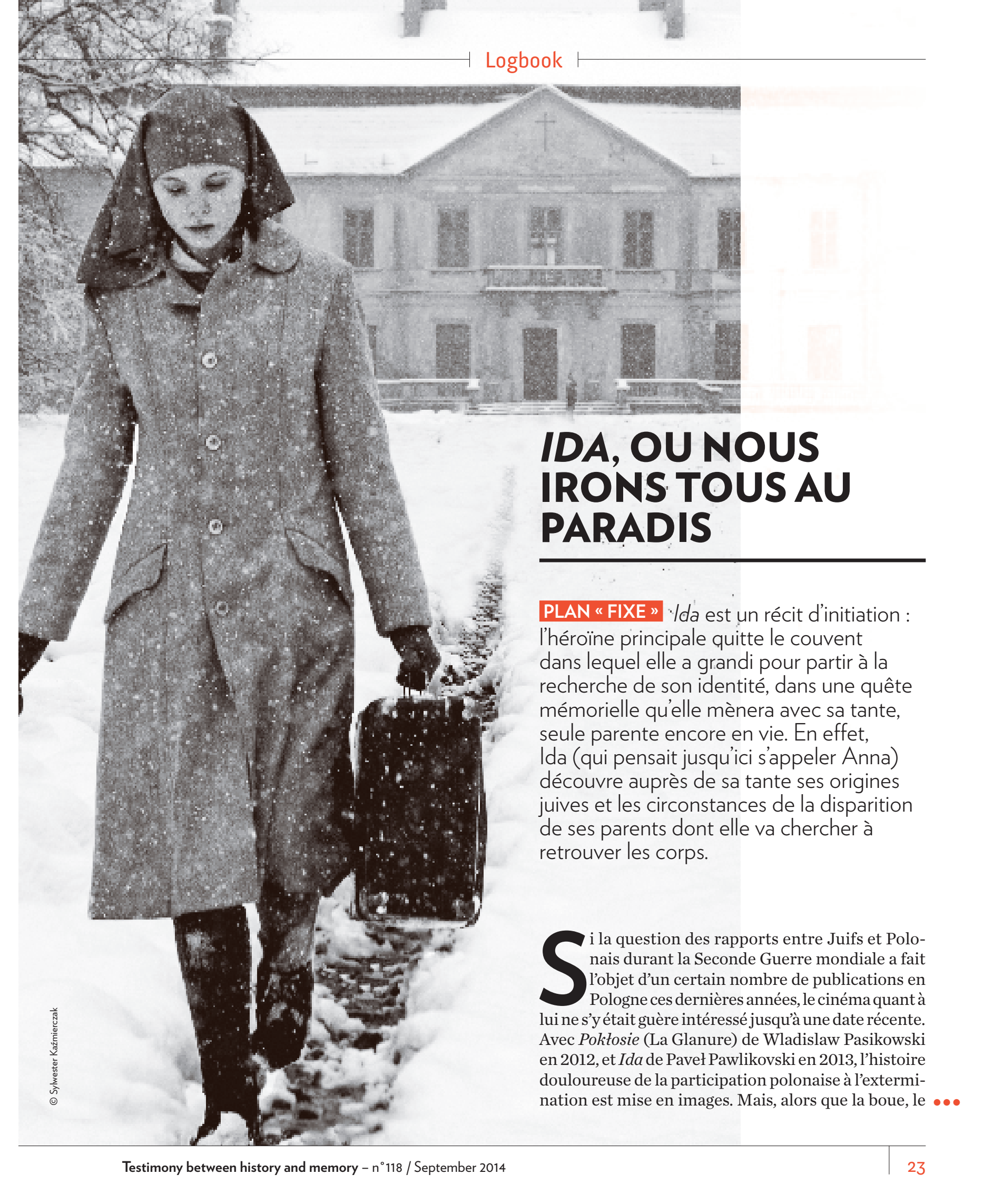


Au cours de la recherche mémorielle qui sert de fil conducteur au récit c'est Wanda (la tante) qui commencerald les témins du massare, tandis qu'Ida reste clôtré les témoins du massacre, tandis qu'Ida reste cloîtré Dans ce

Dans ce contexte, Ida va, pour la première fois s'interroger sur son désir, cest-à-dire sur sa volonté de voir, le re raço de comprendre le monde qui nous entoure. En effet, précé prou 11 y a la comme une infantilisation du personhage: incapable drair suresévénents, elle laissera sa tante le faire à sa place, se réservant uniquement un droit de regard. Celui-ci deviendra de plus en plus listant jusquâ atteindre son apogee au moment de céco renir. En te la construction du personnage. Tout au long du film, re tout à coup, alors même quil n'est plus moné or, tout a coup, alors mème qu'il n'est plus montré les autres plans. Debout à côté de sa tante, nous bu autres plans. Debout à cốe de sa tante, nous ne leyons pas son visage, mais noú pour bo visualiser expesson de son regá demble dailleurs ecrasé par lepoids de ses pêchés. Partel que le présente le film, coup le la Pologe. L' figure religieuse garanted diassurer au gars un

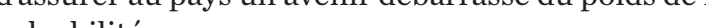
Cette liber

Cette libération du regard d'Ida transparaît de façon plus évidente dans la manifestation de so désir amoureux. Au conss do la quête mémorielle qu'elle mène au côté de sa tante, elle rencontre un jés śxe, elle n’ose pas établir de contact visuel avec lui et ello nose pas etablin de contact visuel avec vi ét se contente dabord dun bref conp d’œil à tracers re rerd volé marque le début de son émapparence, Ces situations se répèteronten s'amplifint jusqua Ces situations se répèteront en samplifiant jusqua ce que, enfin, elle accepte de ne plus dissimuler ce dèsi de savoir mémoriel s'avérant étroitemetlós, Ida de savoir mémoriel savérant étroitement liès, Ida ne peut achever son initiation et se pretendre femme tan quéćch passé. Ce n'est quaprès avoir saisi lanpleur de cette ration ni même de la punition - ce qui ne laisse dans le dispositif du film qu'une possibilité de résorption spirituelle - qu’elle se trouve autorisée d'achever son initiationamo - guelle se trouve l'occurrence l'acceptation de sa vie nonnale.

Pour conclure, on peut dire qu'en comprenan limportance de son regard comme instrument de ment perion de son ide cinté, I Novs avnt explivé, ment personnage de cinéna. Nous avons expliqué, pour portif chose de priniti. Or, cette primitivité sestompe au fur

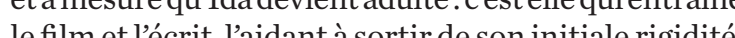
lettećve vette évolution commence dès la première arrivée en ville de lhèroîne.

Regardant par la fenêtre, elle voit défiler les rues et ne peut que constater l'empressement qui y règne. Le nouvement de la camera, uniquement conditionne par celui du tranway, nait de façon fortuite. Ida, soudainement confrontee à son regard qui cherche pour la premiere fois à saissir ane réalité quil lui échappe, fait advenir une inpression chénatographique qui semThat jusque-là inatteignable et mème inenvisageable Tout se passe commestans Car se révelait la naissance du cinéma.

Cependant, l'ensemble du discours se compromet dans un maniêrisme relativement gratuit, une esthé-

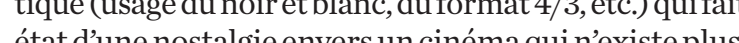
état d une nostalgie envers un cinéma qui n'existe plus, théêtre la peinture ou la photographie et sen dans le tháâtre, la peinture ou la photographie et se méfie de sa propre spécificité. La puissance du discours cinématographique est diluée au sein de lartifice formel La distanciation que le cinéaste aurait dû introduire se forme tout de meme dans lesprit du spectateur, référentiel, mais comme rejet d'une recontairement dont'artificialí és véracité

Gabriel Raichman

Plus d'infos

$\Leftrightarrow$ Ida, de Pawel Pawlikowski, 2013, thig. Prix Fipresci - Toronto 2013; Grand prix - Varsovie 2013

Grand prix - Londres 2013

Témoigner entre histoire et mémoire - n 118 / Septembre 2014 